\title{
EFICIÊNCIA DA APLICAÇÃO DE INSETICIDA QUÍMICO NO SOLO PARA O CONTROLE DE ALPHITOBIUS DIAPERINUS PANZER (COLEOPTERA: TENEBRIONIDAE) EM AVIÁRIO DE FRANGO DE CORTE
}

\section{J.C. Santos ${ }^{1}$, L.F.A. Alves ${ }^{1}$, M.A.U. Opazo ${ }^{3}$, N.R. Mertz $^{5}$, A.M. Marcomini ${ }^{4}$, D.G.P. Oliveira ${ }^{4}$, A.K. Bonini ${ }^{2}$}

${ }^{1}$ Universidade Federal de Viçosa, Departamento de Biologia Animal, Laboratório de Manejo Integrado dePragas de Grãos Armazenados, Av. Peter Henry Rolfs, s/no, CEP 36570-000, Viçosa, MG, Brasil. E-mail: ciências_biologicas@hotmail.com

\section{RESUMO}

Embora os inseticidas químicos sejam os mais utilizados no controle do cascudinho dos aviários (Alphitobius diaperinus), falhas no emprego levam ao insucesso do método. Assim, objetivou-se avaliar o efeito do tratamento do solo com inseticida químico sobre a população do cascudinho em aviário de frango de corte. O experimento foi realizado em um aviário comercial, em Cascavel, PR, acompanhando-se a população dos insetos por 6 meses previamente à aplicação, com armadilhas modificadas de Arends. No solo, a população foi monitorada pela retirada de amostras em três momentos: previamente à aplicação, logo após a ela e 3 meses após o tratamento. Após a retirada da cama, aplicou-se um inseticida comercial (cipermetrina, clorpirifós e citronelal) no solo do aviário ( $5 \mathrm{~L}$ de calda $/ \mathrm{m}^{2}, 2,5 \mathrm{~mL}$ do produto/ $\mathrm{L}$ de água), antes da colocação da nova cama e do alojamento do novo lote. A população dos insetos foi monitorada por igual período e com o mesmo tipo de armadilha. A média obtida antes do tratamento foi de 755 larvas e 89 adultos/armadilha. Após a aplicação, a média de larvas e adultos reduziu-se, para 166 e 23 indivíduos/armadilha, respectivamente. No solo, verificouse elevada mortalidade de larvas e pupas, devido ao contato com o produto que infiltrou, em média, $13 \mathrm{~cm}$.

PALAVRAS-CHAVE: Controle químico, avicultura, cascudinho, produção animal.

\section{ABSTRACT}

EFFICIENCY OF CHEMICAL INSECTICIDE IN SOIL APPLICATIONFOR THE CONTROLOF ALPHITOBIUS DIAPERINUS PANZER (COLEOPTERA: TENEBRIONIDAE) IN THE POULTRY HOUSE. Although the use of insecticides is the most common means to control the lesser mealworm (Alphitobius diaperinus), irregular treatment causes insufficient control. Therefore, the present study was aimed to evaluate the effect of soil treatment with chemical insecticide on the lesser mealworm population. The experiment was carried out in a commercial poultry house, in Cascavel, state of Paraná, Brazil. Before application, in order to quantify beetle population, various Arend's traps were placed in the poultry house litter for 6 months. After the poultry house was cleaned, the insecticide was applied (cypermethrin, chlorpyriphos and citronellal) on the soil (5 $\mathrm{L}$ of water solution $/ \mathrm{m}^{2} ; 2.5 \mathrm{~mL}$ insecticide/ $\mathrm{L}$ of water). Subsequently, the insect population was checked for 6 months. The results showed a mean of 775 larvae and 89 adults/trap before treatment and 166 larvae and 23 adults/traps afterward. In the soil, high larval and pupal mortality were observed, due to contact with the insecticide that infiltrated the soil on average $13 \mathrm{~cm}$ deep.

KEY WORDS: Chemical control, aviculture, lesser mealworm, animal production.

\footnotetext{
${ }^{2}$ Universidade Estadual do Oeste do Paraná, Centro de Ciências Biológicas e da Saúde, Laboratório de Zoologia, Cascavel, PR, Brasil.

${ }^{3}$ Universidade Estadual do Oeste do Paraná, Centro de Ciências Exatas e Tecnológicas, Cascavel, PR, Brasil. ${ }^{4}$ Universidade de São Paulo, Escola Superior de Agricultura "Luiz de Queiroz", Departamento de Entomologia, Fitopatologia e Zoologia Agrícola, Piracicaba, SP, Brasil.

${ }^{5}$ Universidade Federal de Lavras, Departamento de Entomologia, Lavras, MG, Brasil.
} 


\section{INTRODUÇÃO}

O atual sistema de criação e manejo das aves de corte favorece a proliferação do cascudinho (Alphitobius diaperinus Panzer) em aviários de frango de corte principalmente pela constância da temperatura, pelo reaproveitamento da cama a cada troca de lote de aves e pela oferta abundante de alimento e abrigo (Rueda; Axtell, 1997; Ghernaki-Leffer et al., 2001; Silva et al., 2005; VitTORI et al., 2007).

Esses insetos representam grande importância no aspecto econômico e sanitário, pois são ingeridos pelas aves como alimento alternativo, interferindo no seu crescimento e ganho de peso inicial. Além disso, são potenciais veiculadores de diversos patógenos (vírus, fungos, bactérias e protozoários) que causam doenças e mortalidade (Axtell; Arends, 1990; Avancini; Ueta, 1990; McAllister etal.,1995; ChernakiLEFFER et al., 2002; VITTORI et al., 2007).

A proliferação do $A$. diaperinus nos aviários é muito rápida e o aumento populacional ocorre a cada novo lote. Durante o vazio sanitário, os insetos sobrevivem buscando abrigo no solo e, com a chegada do lote seguinte, reinfestam a cama. Isso acontece porque o solo apresenta umidade e temperatura favoráveis ao cascudinho (SAlin et al., 2000; Uemura et al., 2008).

Apesar da recomendação de práticas de manejo do aviário, o controle tem se baseado no uso de inseticidas químicos aplicados somente na superfície da cama. Contudo, o uso incorreto e indiscriminado tornou a estratégia infrutífera, uma vez que a aplicação superficial, ainda que elimine grande quantidade de insetos, permite que rapidamente surjam novos focos de infestação, além de favorecer a seleção de populações resistentes (CHERNAKr-LeFFER, 2004; UEMURA et al., 2008).

Desta forma, considerando os hábitos do inseto, foi testado um método de aplicação de inseticida químico no solo, sendo este o objetivo do presente trabalho.

\section{MATERIAL E MÉTODOS}

Oestudo foi realizado em um aviário comercial de frango de corte vinculado à empresa Diplomata Industrial e Comercial, no Município de Cascavel, Paraná. O aviário apresenta uma área de $1.800 \mathrm{~m}^{2} \mathrm{e}$ capacidade para alojar entre 15 e 18 mil aves. Os sistemas de aquecimento, alimentação e fornecimento de água são automáticos e o piso do aviário de terra batida é recoberto por maravalhas de Pinus com profundidade que variava entre 10 a $15 \mathrm{~cm}$.

$\mathrm{O}$ experimento iniciou-se com a avaliação populacional do cascudinho, semanalmente durante os três primeiros lotes de aves. A amostragem era feita com 15 armadilhas modificadas de Arends (SAFRIT;
AxTelL, 1984), distribuídas de maneira uniforme dentro do aviário em pontos demarcados einstaladas sob os comedouros. Em cada avaliação, as armadilhas eram coletadas e individualizadas em sacos plásticos lacrados, com a reposição de outras no local. A temperatura da cama junto à armadilha também foi monitorada com termômetro digital. O material foi mantido a $-10^{\circ} \mathrm{C}$ por $24 \mathrm{~h}$ para facilitar a contagem das larvas e adultos.

Após a retirada das aves, o aviário foi submetido aos procedimentos usuais de limpeza e desinfecção. Em seguida, aplicou-se o inseticida químico à base de cipermetrina, clorpirifós e citronelal no solo do aviário, utilizando-se $9.000 \mathrm{~L}$ de água, equivalente a $5 \mathrm{Lde}$ calda $/ \mathrm{m}^{2}$, contendo $2,5 \mathrm{~mL}$ do produto/L de água, utilizando-se uma bomba compressora acoplada ao trator e mangueiras de 0,5 polegadas de diâmetro.

Uma semana após a aplicação foi distribuída a nova cama. Durante os 3 lotes consecutivos foram adotados os mesmos procedimentos de amostragem e avaliação populacional descritos anteriormente.

Os dados obtidos após a aplicação do inseticida foram comparados com os dados anteriores e submetidos à análise estatística pelo programa Sisvar (FERREIRA, 1992), com aplicação de análise de variância (ANOVA) e teste Tukey, ambos ao nível de 5\% de significância.

A análise de distribuição espacial do inseto e temperatura da cama foram realizadas no programa Sigmaplot (10.0). Para facilitar a interpretação, os mapas de distribuição espacial dos insetos foram divididos em três áreas distintas: anterior (0-30 $\mathrm{m}$ de comprimento), central (31-95 m de comprimento) e posterior (96-120 $\mathrm{m}$ de comprimento).

Paralelamente, foram feitas amostragens de insetos no solo do aviário, sendo a primeira realizada imediatamente antes da aplicação (pré-aplicação), a segunda logo após (pós-aplicação A) e a terceira após 3 meses do tratamento (pós-aplicação B). Para tal, foram coletadas 6 amostras de solo com profundidade média de $10 \mathrm{~cm}$, distribuídas em três áreas distintas do aviário (terço anterior, médio e posterior), com um marcador de $30 \times 30 \mathrm{~cm}$ (comprimento $\times$ largura) para delimitar todas as áreas de maneira uniforme. As amostras foram individualizadas em sacos plásticos e levadas ao laboratório para contagem de larvas, pupas e adultos, vivos e mortos.

Os dados de insetos vivos e mortos foram analisados separadamente quanto à análise de variância (ANOVA) e as médias comparadas entre si pelo teste Tukey, a 5\% de significância, utilizando o programa Sisvar (FERREIRA, 1992). Quando necessário, os dados foram devidamente transformados.

Para determinar a densidade das partículas do solo utilizou-se a metodologia da EMBRAPA (1997). Assim, 13 amostras de solo foram coletadas em pon- 
tos aleatórios do aviário, entre 0 e $10 \mathrm{~cm}$ de profundidade, utilizando-se um anel volumétrico, o qual foi levado a estufa $\left(105^{\circ} \mathrm{C}\right)$ por 24 horas. Os dados foram submetidos aos cálculos para se determinar sua densidade, porosidade e estimativa da lâmina de água infiltrada.

\section{RESULTADOS E DISCUSSÃO}

Previamente à aplicação do produto, a média dos insetos coletados em todas as amostragens realizadas foi 754,9 larvas e 88,9 adultos, elevando-se ao longo do tempo, pois o número médio de larvas variou entre 274,1 (1lote) a 1105,0 (2lote), apresentando-se mais elevada que a média de adultos, de 39,2 (1 lote) a 128,4 (3 lote) insetos. A temperatura média da cama do aviário também apresentou variações de $29,5^{\circ} \mathrm{C}$ no 1 o lote e $34,4^{\circ} \mathrm{C}$ no 3 ㅇ lote (Tabela 1 ). Essa significativa elevação da temperatura média entre os lotes é decorrência do acúmulo de ração e fezes, o qual favoreceu a atividade microbiana e tornou o ambiente propício ao desenvolvimento da praga (Chernaki-Leffer; Almeida, 2001; ChernaKiLEFFER et al., 2007). Tais resultados corroboram os dados obtidos por CHERNAKI-LefFer et al. (2007) e UEMURA et al. (2008), que também verificaram grande variação no número de insetos, e maior número de larvas do que de adultos nas armadilhas.

Nas amostragens após a aplicação verificou-se o mesmo perfil populacional com número médio de larvas excedendo o de adultos e com valores crescentes ao longo do tempo. Fato também verificado com os dados de temperatura (Tabela 1).

Observou-se variação na distribuição espacial dos insetos no aviário ao longo do tempo, sendo que a infestação inicial de adultos estava aglomerada na área anterior e começo da área central, passando a se distribuir para a área posterior no lote seguinte. Contudo, no lote 3 , os insetos voltaram a se concentrar em três pequenos focos distintos, sendo dois localizados no final da área central e início da área posterior e outro, na área anterior, com as médias variando entre 210 a 360 insetos nas armadilhas (Fig. 1).

Em relação às larvas, no lote 1 haviam focos de infestação, principalmente, na área anterior e no início da área central (Fig. 1). Outra faixa de distribuição, porém com menor amplitude, foi verificada no final da área posterior do aviário, com média de 350 a 700 insetos nas armadilhas. Nolote 2, de forma semelhante ao ocorrido com os adultos, as larvas já haviam se distribuído por toda a extensão do aviário, porém, concentradas, principalmente, na área central (médias entre 1.250 e 1.750 insetos nas armadilhas). A concentração das larvas manteve-se nolote 3, porém, em uma estreita faixa que abrangia todo o comprimento do aviário, entre 9 e 13 m delargura, com médias entre 700 e 1.750 insetos (Fig. 1).

Tal padrão de distribuição populacional de larvas eadultos éjustificado em função das temperaturas da cama em que as mais elevadas foram verificadas na área anterior e central do aviário $\left(34\right.$ a $\left.36^{\circ} \mathrm{C}\right)$, em função, principalmente, da localização do aquecedor automático que se encontra instalado entre essas áreas (Fig. 3).

Após a aplicação, a tendência da distribuição populacional, tanto de larvas como de adultos, foi semelhante à observada anteriormente ao tratamento, contudo, os valores obtidos secundariamente foram muito inferiores, em função da atividade do inseticida. (Fig. 2).

Comparando-se os lotes equivalentes verificou-se que a população de $A$. diaperinus foi mais elevada na avaliação pré-tratamento, reduzindo consideravelmente pós-tratamento, tendo média geral 843,8 e189,0 insetos por armadilha, respectivamente (Tabela 1). Esses resultados comprovam a eficiência do uso de inseticida químico nessa estratégia de controle, pois o encharcamento do solo com aplicação em altovolume atingiu os insetos nesse substrato, causando mortalidade e reduzindo o seu número na superfície da cama.

Tabela 1 - Número médio de larvas e adultos de Alphitobius diaperinus coletados nas armadilhas e temperatura média da cama, por lote de aves, antes e após a aplicação de inseticida no solo do aviário.

\begin{tabular}{|c|c|c|c|c|c|c|}
\hline \multirow[b]{2}{*}{ Parâmetro } & \multicolumn{2}{|c|}{ Lote 1} & \multicolumn{2}{|c|}{ Lote 2} & \multicolumn{2}{|c|}{ Lote 3} \\
\hline & Pré & Pós & Pré & Pós & Pré & Pós \\
\hline Larva & $247,1 \pm 51,72 \mathrm{a}$ & $0,6 \pm 0,35 b$ & $1105 \pm 99,83 a$ & $67,9 \pm 28,8 b$ & $912,8 \pm 127 a$ & $430,7 \pm 87,63 b$ \\
\hline Adulto & $39,2 \pm 13,83 a$ & $0,5 \pm 0,13 b$ & $99,3 \pm 21,62 a$ & $6,6 \pm 1,43 b$ & $128,4 \pm 29,72 a$ & $60,8 \pm 19,61 b$ \\
\hline Temperatura & $29,5 \pm 0,61 \mathrm{a}$ & $30,1 \pm 0,35 a$ & $33,5 \pm 0,39 a$ & $31,3 \pm 0,35 b$ & $34,4 \pm 0,38 \mathrm{a}$ & $33,3 \pm 0,55 a$ \\
\hline
\end{tabular}

Dados originais apresentados; para análise estatística os dados foram transformados em $\sqrt{x+1}$.

Médias $( \pm E P)$ seguidas de mesma letra na linha, para cada um dos lotes, não diferem entre si pelo teste de Tukey ( $p<$ $0,05)$. 

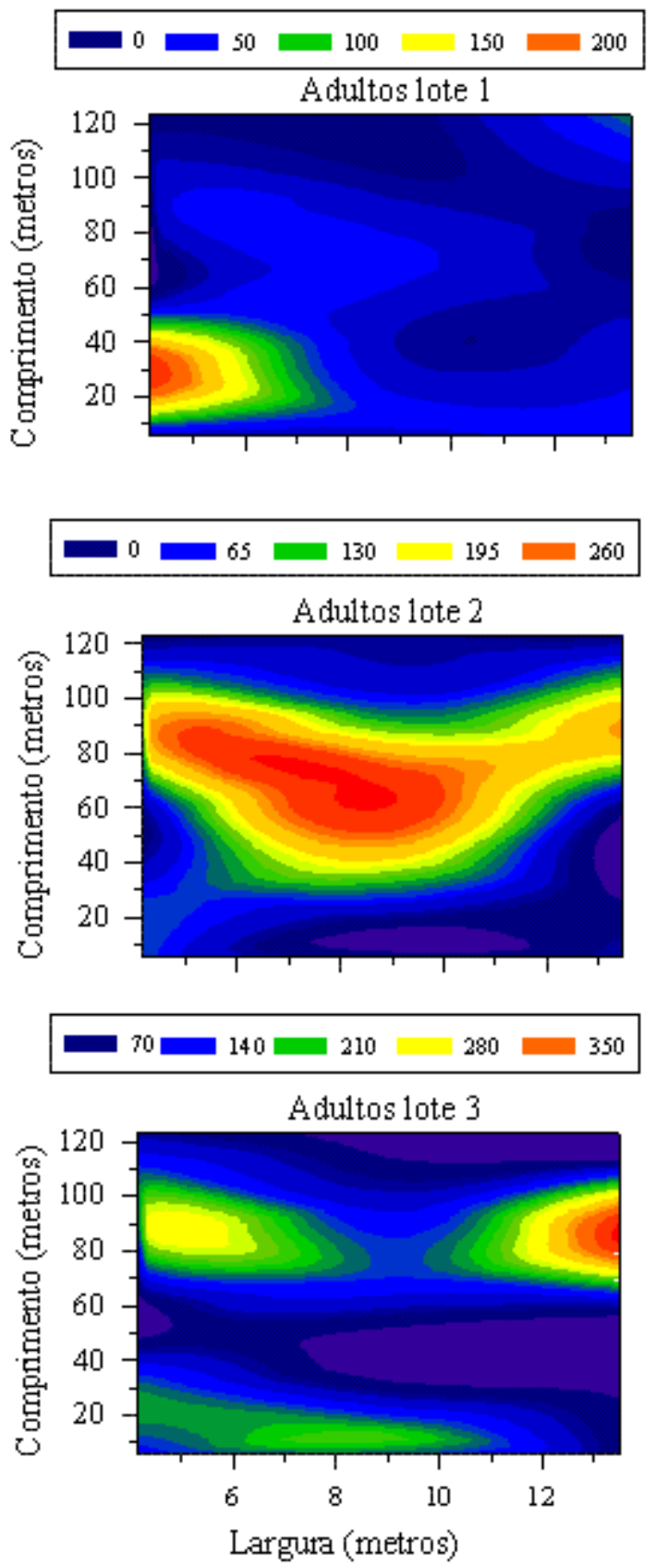
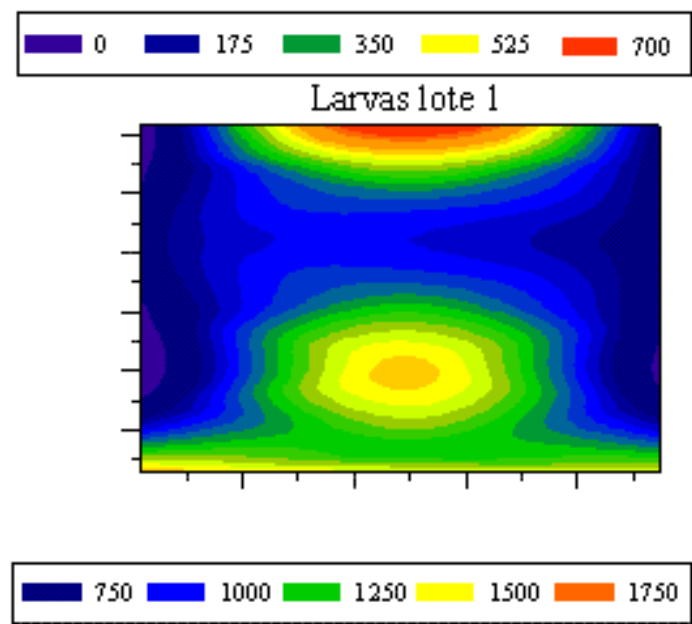

Larvas lote 2
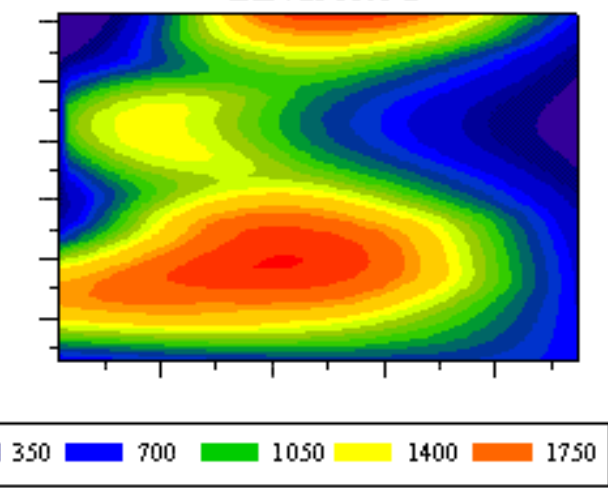

Larvas lote 3

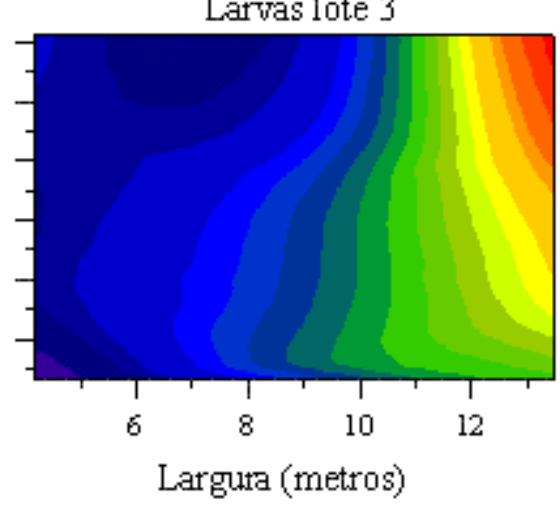

Fig. 1 - Distribuição espacial de adultos e larvas de Alphitobius diaperinus por lote de aves, previamente a aplicação de inseticida no solo do aviário.

Os resultados obtidos foram mais expressivos indicando a eficácia do tratamento, se comparados com os de KHAN et al. (1998). Os autores realizaram tratamento completo do aviário (parede, teto e superfície do solo) após a retirada das aves e da cama, porém, aplicaram inseticida tetraclorvinfós em pó, obtendo controle da população do cascudinho por 6 semanas, o que corresponderia a um lote de criação de aves.

Da mesma forma, CHERNAKI-LeFfer et al. (2007) verificaram que a aplicação de inseticida à base de cipermetrina pulverizado na superfície da cama sob comedouros quando a população se encontrava elevada, ainda que tenha provocado uma redução no número de insetos, não impediu a imediata recuperação no lote subsequente.

Vale ressaltar que os resultados aqui obtidos referem-se à uma única aplicação, enquanto que SALIN et al. (2003) obtiveram sucesso no controle docascudinho fazendo aplicações sistemáticas de inseticida a cada saída e entrada de novo lote de aves, porém, não em aplicações de grande volume de produto. 

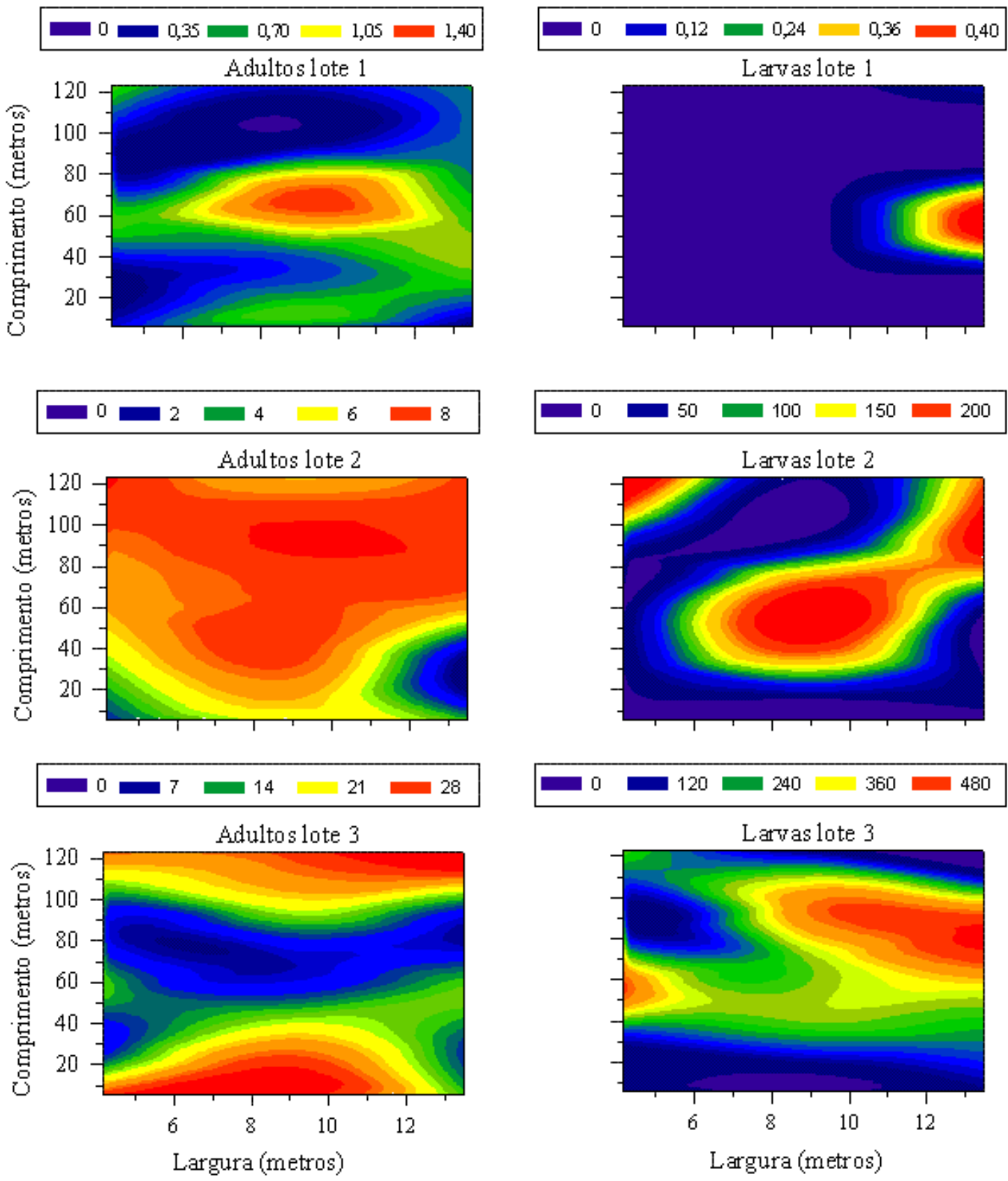

Fig. 2 - Distribuição espacial de adultos e larvas de Alphitobius diaperinus por lote de aves, posteriormente a aplicação de inseticida no solo do aviário.

O método tradicional de aplicação de inseticida em aviários comerciais envolve a pulverização em todo o aviário após a retirada completa da cama, lavagem e desinfecção do galpão, embora a maioria dos produtores também pulverize a cama entre os lotes de aves. O tratamento é feito em todas as laterais internas, ao redor de postes, silos internos e sobre a cama velha amontoada. São, em tese, de fácil adoção e penetração em superfícies porosas, fendas e rachaduras (Chernaki-Leffer et al., 2001) e (Pinto Junior, informação pessoal). Apesar das recomendações, muitas vezes os produtores deixam de tratar todo o aviário, fazendo uso de inseticidas químicos apenas junto às paredes, frestas e sob comedouros e, nas épocas em que é perceptível uma alta população de insetos, quando o controle se torna mais difícil e custoso (Prevent News, 1998).

Pode-se, em parte, explicar tal procedimento pelo fato de muitas vezes ser utilizado o pulverizador costal, que se torna dispendioso fisicamente caso se decida por tratar todo o aviário com tal equipamento. Isso inviabiliza o processo e exige que o produtor adquira equipamentos mais adequados que, na maioria das vezes, são caros (Prevent News,1998). 

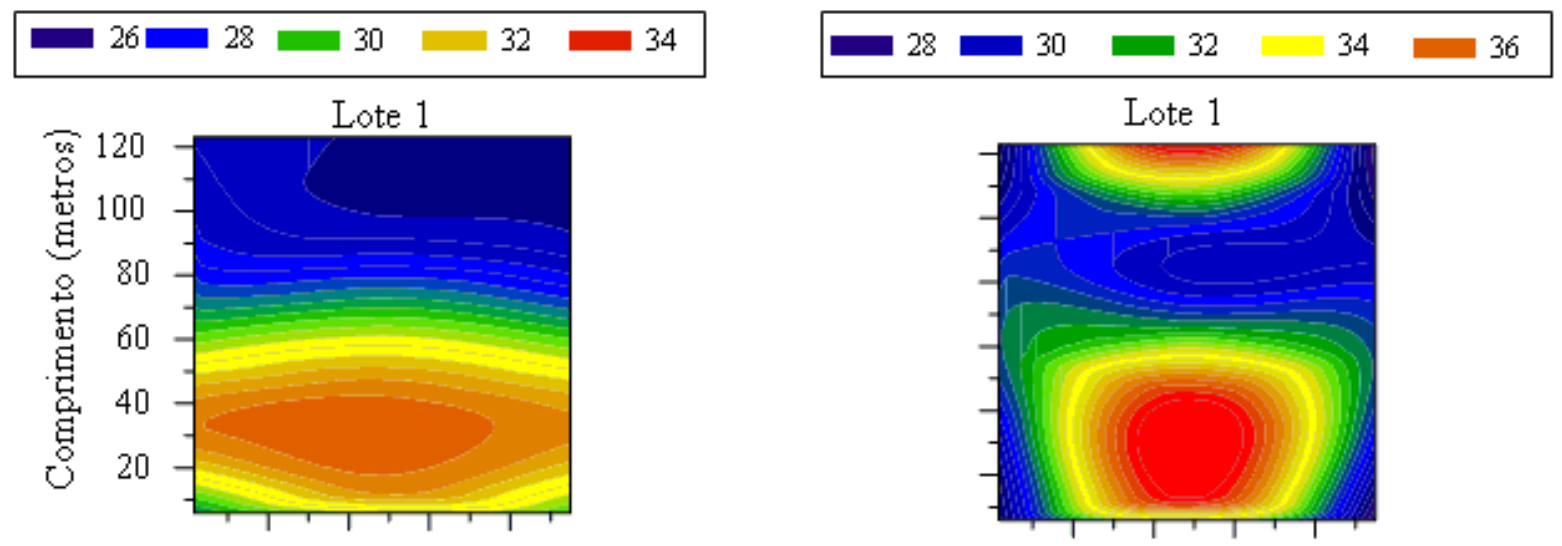
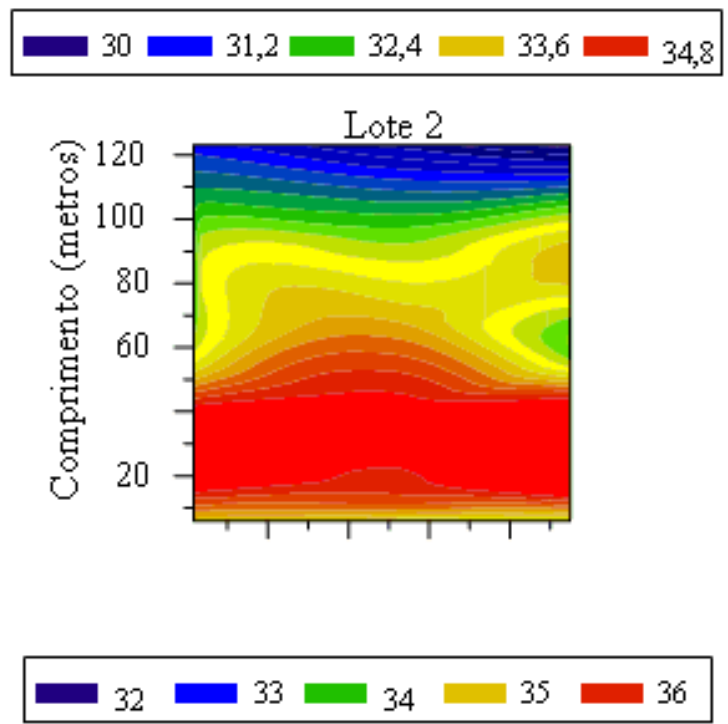

Lote 3

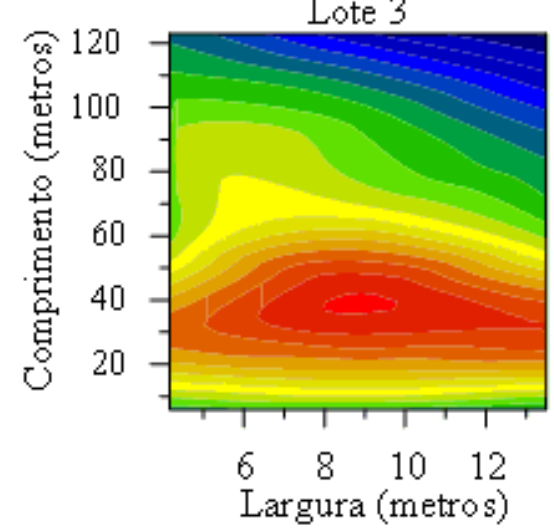

$\begin{aligned} & 28,6 \\ & 29,7 \\ & 30,8\end{aligned} \mathbf{3 1 , 9}=33,0$

Lote 2

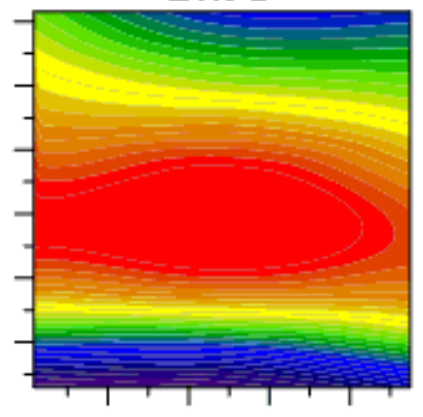

$30,4 \square 31,2 \square 32,0 \quad 32,6$

Lote 3

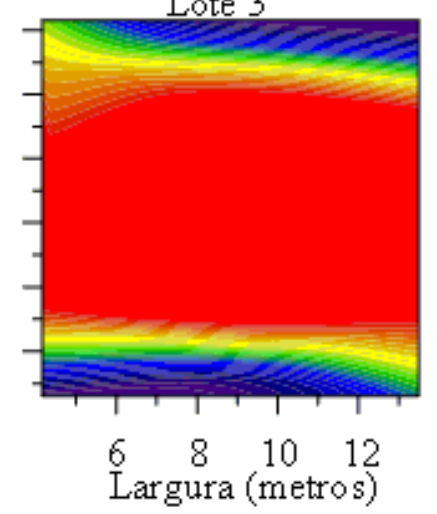

Fig. 3. - Distribuição espacial da temperatura da cama, por lote de aves, antes e após a aplicação de inseticida no solo do aviário.

Estudos prévios comprovam que a aplicação de inseticida na cama, apesar de eficiente no controle, está sujeita à interferência da cama, visto que, quando ela se encontra com aproximadamente $15 \mathrm{~cm}$ de espessura o efeito residual é reduzido (Matias, 1992).
Em condições de campo, Matias (2005) verificou que a aplicação de piretrioides e organofosforados nos locais onde havia concentração de insetos (como postes, muretas e sob comedouros) proporcionou controle até o sétimo dia pós-aplicação. No entanto, 
esses ressurgiram no início do 2o e 3o lote. O autor conclui que, além de revolver a cama após a aplicação, deve-se utilizar inseticida entre os lotes, quando a concentração desses é mais elevada, até que a cama seja trocada, e então se efetue uma nova pulverização em toda a extensão do aviário.

Por outro lado, OLIVEIRA et al. (informaçãopessoal) obtiveram bons resultados em testes preliminares de tratamento de solo, utilizando círculos de metal, enterrados a $5 \mathrm{~cm}$. Os tratamentos com inseticida (cipermetrina 1 L/100 L) e volume de calda de 20, 40 e $80 \mathrm{~L} / \mathrm{m}^{2}$ reduziram em mais de $95 \%$ a emergência dos insetos adultos.

Muitas vezes, o tratamento da cama acaba sendo ineficaz, pois, além de atingir insetos presentes apenas na superfície, a alcalinidade da cama, devido aos métodos de manejo, promove a desestabilização do princípio ativo do produto, reduzindo o efeito residual (GEDEN et al., 1998). Em consequência, há rápida reinfestação, exigindo repetidas aplicações, o que favorece a seleção de populações resistentes, como constatado para cipermetrina e diclorvós (CHERNAKILEFFER, 2004).

Quanto à análise da população no solo, verificouseque não houve variação significativa na média total de adultos coletados nas amostragens de pré e pósaplicação do inseticida. Contudo, em relação às larvas, previamente à aplicação eram encontradas em média 1,3 larvas, aumentando significativamente à medida em que foram realizadas novas avaliações, pós-aplicação A (25,0 larvas) e pós-aplicação B (53,3 larvas). Baixa mortalidade de larvas foi verificada na amostragem pré-aplicação (2,2 larvas), diferindo das duas amostragens pós-aplicação (A e B), com mais de 35 indivíduos mortos coletados (Tabela 2).

A média total de pupas vivas $(23,5)$ e mortas $(21,0)$ também foi semelhante nas avaliações do solo do aviário. O número de pupas vivas no solo não diferiu entre as amostragens de pré-aplicação (0,4 pupas) e pós-aplicação A (12 pupas), porém, houve um au- mento significativo dessas na avaliação pós-aplicação $B$ (58 pupas). Baixa mortalidade para essa fase foi constatada na amostra pré-aplicação de inseticida $(0,4$ pupas) e manteve-se desta forma na avaliação pós-aplicação A (15,6 pupas), contudo, verificou-se maior mortalidade de pupas na terceira avaliação (pós-aplicação B), com mais de 47 indivíduos, denotando-se que o inseticida agiu em longo prazo, assim como verificado para a fase larval (Tabela 2).

Em geral, constatou-se baixa população de insetos na avaliação pré-aplicação do inseticida, apesar de se esperar um número maior, uma vez que eles se refugiam no solo durante o período de saída das aves e limpeza do aviário. Provavelmente isto ocorreu em função das amostragens terem sido realizadas aleatoriamente no aviário, e não somente sob os comedouros e junto às paredes, que são locais de grande aglomeração de insetos (SALIN et al., 2000).

Já a existência de insetos vivos no solo após o tratamento com inseticida pode estar relacionada à infiltração desuniforme do produto no solo, o qual pode ter atingido menor profundidade em relação ao local de abrigo dos insetos. Como o aviário apresenta áreas com diferentes níveis de compactação, o contato pode ter ocorrido somente quando os insetos migraram para a superfície, justificando a menor incidência de insetos coletados na superfície da cama posteriormente a aplicação.

Em relação às características físicas do solo, verificou-se que os valores de densidade de solo encontrados nas diferentes amostras do aviário apresentaramse de forma heterogênea, entre 1,13 e $1,38 \mathrm{mg} / \mathrm{m}^{3}$, com média de $1,26 \mathrm{mg} / \mathrm{m}^{3}$. Já a densidade de partícula foi de $2,76 \mathrm{mg} / \mathrm{m}^{3}$ e a média da porosidade do solo entre as diferentes amostras (valores entre 0,50 e 0,59 dm/ $\mathrm{dm}^{3}$ ) foi de $0,54 \mathrm{dm} / \mathrm{dm}^{3}$ ou $54 \%$. Com isso, constatouse que a lâmina esperada para a infiltração de água no solo do aviário foi de $125 \mathrm{~mm}$, indicando, dessa maneira, que a calda (inseticida + água) aplicada infiltrou até essa profundidade.

Tabela 2 - Número médio de larvas e adultos deAlphitobius diaperinus nas armadilhas de solocoletadas prée pós-aplicação de inseticida no solo do aviário.

\begin{tabular}{|c|c|c|c|c|c|c|}
\hline \multirow[t]{2}{*}{ Amostragem } & \multicolumn{2}{|c|}{ Larvas } & \multicolumn{2}{|c|}{ Pupas } & \multicolumn{2}{|c|}{ Adultos } \\
\hline & Vivos & Mortos & Vivos & Mortos & Vivos & Mortos \\
\hline Pré-aplicação & $1,3 \pm 0,56 c$ & $2,2 \pm 1,03 b$ & $0,4 \pm 0,18 b$ & $0,4 \pm 0,18 b$ & $54,7 \pm 24,08 \mathrm{a}$ & $23,6 \pm 7,57 a$ \\
\hline Pós-aplicação A & $25,0 \pm 7,71 b$ & $36,3 \pm 15,11 a$ & $12 \pm 4,08 b$ & $15,6 \pm 9,27 b$ & $25,1 \pm 8,89 a$ & $21,1 \pm 4,11 \mathrm{a}$ \\
\hline Pós-aplicação B & $53,3 \pm 11,39 a$ & $37,6 \pm 10,52 a$ & $58 \pm 16,05 a$ & $47,1 \pm 12,74 a$ & $89,8 \pm 24,76 a$ & $48,7 \pm 14,0 \mathrm{a}$ \\
\hline Média & 26,5 & 25,4 & 23,5 & 21,0 & 56,5 & 31,1 \\
\hline
\end{tabular}

Dados originais apresentados; para análise estatística os dados foram transformados em $-\sqrt{x+1}$

Médias $( \pm \mathrm{EP})$ seguidas de mesma letra minúscula na coluna para o mesmo estágio de desenvolvimento, não diferem entre si, pelo teste de Tukey $(\mathrm{p}<0,05)$. 
Apesar de não ter sido realizada análise química do solo, supõe-se que altas concentrações salinas $(\mathrm{P}$, $\mathrm{KCa} \mathrm{Mg}$ ) no solo do aviário, tal como constatado por Oliveira et al. (informação pessoal), geram melhor translocação e redistribuição de água o que possivelmente pode ter contribuído para a quantidade de infiltração obtida neste experimento. Resultados semelhantes de densidade do solo $\left(1,35 \mathrm{mg} / \mathrm{m}^{3}\right)$ e porosidade total $(45 \%)$ foram obtidos pelos mesmos autores, que constataram velocidade de infiltração vertical da água no solo de $2 \mathrm{~mm} / \mathrm{h}$.

Considerando que o solo no interior do aviário é compactado, resultados satisfatórios no controle de A. diaperinus no solo só são possíveis, segundoOliveIRA et al. (informação pessoal), devido ao comportamento desse inseto de abrir galerias para empupar (aproximadamente $10 \mathrm{~cm}$ ) que permite maior infiltração da água e saturação do solo, ocasionando sua mortalidade. Esse comportamento auxilia na descompactação, no aumento da porosidade e diminuição da densidade desse substrato, fato que contribuiu para uma maior infiltração do inseticida, principalmente em áreas mais profundas.

Assim, o tratamento do solo com inseticida químico mostrou-se eficiente e influenciou a população do inseto, reduzindo a quantidade de indivíduos e afetando sua distribuição.

\section{AGRADECIMENTOS}

À Fundação Araucária e às empresas Globoaves Agro Avícola eDiplomata Industrial e Comercial pelo auxílio financeiro para realização da pesquisa, e ao CNPq pela concessão de bolsas PIBIC e produtividade em pesquisa.

\section{REFERÊNCIAS}

AVANCINI, R.M.P.; UETA, M.P. Manure breeding insects (Diptera and Coleoptera) responsible for cestoidosis in caged layer hens. Journal of Applied Entomology, v.110, n.3, p.307-312, 1990.

AXTELL, R.C.; ARENDS, J.J. Ecology and management of arthropod pests of poultry. Annual Review of Entomology, v.35, p.101-126, 1990.

CHERNAKI-LEFFER, A.M. Dinâmica populacional, estimativa da resistência a inseticidas e alternativas de controle para o cascudinho Alphitobius diaperinus (Panzer, 1797). 2004. 123f. Tese (Doutorado em Ciências Biológicas - Área de Entomologia), Universidade Federal do Paraná, Curitiba, 2004.

CHERNAKI-LEFFER, A.M.; ALMEIDA, L.M. Exigências térmicas, período de desenvolvimento e sobrevivência de imaturos Alphitobius diaperinus (Panzer) (Coleoptera: Tenebrionidae). Neotropical Entomology, v.30, n.3, p.365-368, 2001.

CHERNAKI-LEFFER, A.M.; LAZZARI, F.A.; LAZZARI, F.M.N.; ALMEIDA, L.M. Controle do cascudinho. Avicultura Industrial, v.92, n.1094, p.22-25, 2001.

CHERNAKI-LEFFER, A.M.; BIESDORF, S.M.; ALMEIDA, L.M.; LEFFER, E.V.B.; VIGNE, F. Isolamento de enterobactérias em Alphitobius diaperinus e cama de aviários no oeste do estado do Paraná, Brasil. Revista Brasileira de Ciência Avícola, v.4, n.3, p.243-247, 2002.

CHERNAKI-LEFFER, A.M.; ALMEIDA, L.M.; SOSAGÓMEZ, D.R.; ANJOS, A.; VOGADO, K.M.

Populational fluctuation and spatial distribution of Alphitobius diaperinus (Panzer) (Coleoptera:

Tenebrionidae) in a poultry house, Cascavel, Parana state, Brazil. Brazilian Journal of Biology, v.67, n.2, p.209$213,2007$.

EMBRAPA. Brasil. Manual de métodos de análise do solo. 2. Rio de Janeiro: Embrapa-CNPS, 1997. 99p.

FERREIRA, D.F (Ed.). SISVAR (Sistema para análise de variância para dados balanceados). Lavras: UFLA, 1992. $79 \mathrm{p}$.

GEDEN, C.J.; AXTELL, J.J.; RUTZ, D.A.; STEINKRAUS, D.C. Laboratory evaluation of Beauveria bassiana (Moniliales: Moniliaceae) against the lesser mealworm, Alphitobius diaperinus (Coleoptera:

Tenebrionidae), in poultry litter, soil, and a pupal trap. Biological Control, v.13, n.2, p.71-77, 1998.

KHAN, B.A.; DAY, P.A.; GOONEWARDENE, L.A.; ZUIDHOF, M.J.; HAWKINS, G. Efficacy of tetrachlorvinphos insecticide dust against darkling beetles in commercial broiler chicken barns.

Canadian Journal of Animal Science, v.78, n.4, p.723-725, 1998.

MATIAS, R.S. Controle de Alphitobius diaperinus em piso de aviários. Pesquisa Agropecuária Brasileira, v.27, n.1, p.205-207, 1992.

MATIAS, R.S. Controle de Alphitobius diaperinus com inseticidas piretróides e organofosforados em granjas avícolas no sul do Brasil. A Hora Veterinária, v.25, p.4751, 2005.

MCALLISTER, J.C.; C.D. STEELMAN, L.A. NEWBERRY; SKEELES, J.K. Isolation of infectious bursal disease virus from the lesser mealworm, Alphitobius diaperinus (Panzer). Poultry Science, v.74, n.1, p.45-49, 1995.

PREVENT NEWS. Biologia e controle do Alphitobius diaperinus. Curitiba: Prevent News, 1998. n.15, p.1-2. 
RUEDA, L.M.; AXTELL, R.C. Artropods in litter of poutry (broiler chicken and turkey) houses. Journal of Agricultural and Urban Entomology, v.14, n.1, p.81-91, 1997.

SAFRIT, R.D.; AXTELL, R.D. Evaluations of sampling methods for darkling beetles (Alphitobius diaperinus) in the litter of turkey and broiler houses. Poultry Science, v.63, n.12, p.2368-2375, 1984.

SALIN, C.; DELETTRE, Y.R.; CANNAVACCIUOLO, M.; VERNON, P. Spatial distribution of Alphitobius diaperinus (Panzer) (Coleoptera: Tenebrionidae) in the soil of a poultry house along a breeding cycle. European Journal of Soil Biology, v.36, n.2, p.107-115, 2000.

SALIN, C.; DELETTRE, Y.R.; VERNON, P. Controlling the lesser mealworm Alphitobius diaperinus (Coleoptera: Tenebrionidae) in broiler and turkey houses: field trials with a combined insecticide treatment: insect growth regulator and pyrethroid. Journal of Economic Entomology, v.96, n.1, p.126-130, 2003.
SILVA, A.S.; HOLF, G.; DOYLE, R.L.; SANTURIO, J.M.; MONTEIRO, S.G. Ciclo biológico do cascudinho Alphitobius diaperinus em laboratório. Acta Scientiarum, v.33, n.2, p.177-181, 2005.

UEMURA, D.H.; ALVES, L.F.A.; OPAZO, M.A.U.; ALEXANDRE, T.M.; OLIVEIRA, D.G.P.; VENTURA, M.U. Distribuição e dinâmica populacional do cascudinho Alphitobius diaperinus (Coleoptera: Tenebrionidae) em aviários de frango de corte. Arquivos do Instituto Biológico, São Paulo, v.75, n.4, p.429435, 2008.

VITTORI, J.; SCHOCKEN-ITURRINO; R.P.; TROVÓ, K.P.; RIBEIRO; C.A.M.; BARBOSA, G.G.; SOUZA, L.M.; PIGATTO, C.P. Alphitobius diaperinus como veiculador de Clostridium perfingens em granjas avícolas do interior paulista. Ciência Rural, v.37, n.3, p.894-896, 2007.

Recebido em 30/4/08

Aceito em 18/5/09 